\title{
i[CREMF
}

\section{The Role of Absorptive Capacity and Disseminative Capacity on Knowledge Internalization of Organizational Practices}

\author{
Helen Aquino $^{1 *}$, José Márcio de Castro ${ }^{2}$, Laurent Scaringella ${ }^{3}$ \\ ${ }^{1 *}$ Ezequiel Dias Foundation and Pontifical Catholic University of Minas Gerais, Brazil \\ ${ }^{2}$ Pontifical Catholic University of Minas Gerais, Brazil \\ ${ }^{3}$ ESC Rennes School of Business, France
}

\begin{abstract}
The implementation of knowledge has been considered as a positive and final result of the transfer process. This means that we know little about whether the transferred knowledge was appropriated, absorbed or even used by the receiving firm. Thus, the aim of this research is to take the knowledge internalization as a measure to analyze the effectiveness of the knowledge transfer process. That is, if, in fact, the transferred knowledge is internalized in the organizational routines and understands the role of absorptive and disseminative capacity in the process. To this end, a longitudinal case study of a qualitative nature was conducted, involving data and information collection over nine years (2008-2016), 13 interviews taking as a case one of the most important public health, science and technology institutions in Brazil. The findings show that a larger source's disseminative capacity contributes to a greater appropriation of knowledge by the receiver and a reduction in the internalization time. Moreover, a larger receiver's absorptive capacity contributed to a greater appropriation of knowledge and reduced the time taken for internalization. The main contribution is providing a deeper understanding of the knowledge internalization as an effective result in transfer process, including an understanding of the role of absorptive and disseminative capacity in the internalization process. Furthermore, this study provides four propositions to explain the phenomenon.
\end{abstract}

Keywords: Absorptive Capacity, Disseminative Capacity, Knowledge Transfer, Knowledge Internalization. 


\section{itRenEF}

\section{Introduction}

Over the past two decades, knowledge transfer has been one of the most strategic processes for organizations, either because of its direct relationship with innovation or its decisive role in improving organizational performance and obtaining competitive advantages (Argote \& Fahrenkopf, 2016; Szulanski et al., 2016). The literature points out that a firm can improve its capabilities or minimizes its exposure to market risks and uncertainties by acquiring complementary external knowledge (Argote \& Fahrenkopf, 2016).

In addition to the advantages attributed to the acquisition of organizational knowledge, the difficulty of evaluation of knowledge transfer results has emerged in the literature (Argote \& Fahrenkopf, 2016). Under these considerations, one aspect that deserves attention involves evaluating not only the implementation of new knowledge (Mu et al., 2010) but especially if the transferred knowledge has been internalized i.e., actively adopted by the receiver firm (Kostova \& Roth, 2002), better responding to internal and market needs (Argote \& Fahrenkopf, 2016).

In this sense, the knowledge internalization can be combined with several factors that can influence the transfer process and for this reason, must be taken into account. Two important elements often studied separately in the literature, can influence the knowledge internalization: the receiver's absorptive capacity (Patterson \& Ambrosini, 2015; Volberda et al., 2010) comprises the phases of acquisition, assimilation, transformation and application of knowledge (Zahra \& George, 2002), and the source's disseminative capacity (Sroka et al., 2014), refers to the source's motivation to carry out the transfer process and its ability to teach the new knowledge (Mu et al., 2010). Thus, an incomplete cycle of knowledge transfer (Tsai $\&$ Lee, 2006) can result in the failure of the process (Kostova \& Roth, 2002).

Starting from the premise that an effective knowledge transfer process only happens when the knowledge is internalized by the receiving company, the aim of this research is to take the knowledge internalization to analyze the effectiveness of the knowledge transfer process and understanding the role of absorptive and disseminative capacity in the process. To achieve this purpose a longitudinal case study (2008-2016) was conducted, taken as a case one of the most important public health, science, and technology institutions in Brazil, Ezequiel Dias Foundation - Funed. The foundation presented as an ideal case for having undergone a process of transferring quality practices which aims at the development, manufacture and supply of more efficient and safer products and services.

Given this, this research contributes to the advance in the understanding of knowledge internalization as an effective result in knowledge transfer process and an understanding of the role of receiver's absorptive capacity and sender's disseminative capacity in the knowledge internalization process of organizational practices. Furthermore, as a research contribution, a theoretical model is proposed to explain the phenomenon. 


\section{i[CREMF}

\section{Theoretical Background}

\subsection{Knowledge Internalization in Organizational Practices Transfer}

One of the knowledge that is often the object of transfer refers to organizational practices as an important resource to ensure productivity, growth and organizational survival (Szulanski et al., 2016). An organizational practice can be understood as the routine use of knowledge to perform a particular function (Kostova \& Roth, 2002).

However, an organization may only deploy a received practice, but may not internalize it. The result can be a formal or ceremonial adoption of a practice whose history in the organization tends to be ephemeral. That is, a knowledge that has not been internalized will be discarded over time (Szulanski et al., 2016). In other words, the incomplete cycle of transference, i.e. only implementation without the internalization of knowledge has been largely responsible for the failure of transfer processes (Kostova \& Roth, 2002).

For the outcome of the knowledge transfer process to be truly effective and incorporated, the receiver must internalize the knowledge, that is, incorporate new external knowledge into their knowledge bases (Wipawayangkool \& Teng, 2016). Thus, the knowledge internalization is directly intertwined with the ability of the organization to value it, that is, to take it as valuable, useful and capable of adding gains to the organizational routine (Kostova \& Roth, 2002; Easterby-Smith et al., 2008; Wipawayangkool \& Teng, 2016) and be relevant to the receiver's present and future needs. According to Kostova and Roth (2002), "internalization is the state in which the recipient's employees see the practice as valuable to the unit and become committed to it." (p. 217). It is from this perception that the organization then becomes committed to such practice (Kostova \& Roth, 2002).

The internalization of a practice from transference can be understood from two attributes: first, the receiver's level of appropriation of the transferred knowledge and second, the time spent internalizing it (Ancori, Bueth \& Cohendet, 2000; Szulanski et al., 2016) which was conceived here as the extension of the knowledge internalization. The appropriation of knowledge is the result of combining existing knowledge with new knowledge, far beyond just moving knowledge from source to recipient. It is, in fact, a synergy in which the combination of knowledge is greater than the simple sum of knowledge and as such takes time to be incorporated and internalized in the receiver's organizational routine (Ancori et al., 2000). For Wipawayangkool and Teng (2016) the internalization of knowledge is analogous to learning, since this is a process of knowledge appropriation that occurs in the sourcereceptor dyad. Since the transferred knowledge is appropriated by the receiver company, it tends to obtain better, longer-lasting and more authentic results in its operations, i.e. internalization enhances the benefits of knowledge transfer (Mu et al., 2010).

In addition to the appropriation of knowledge, another relevant attribute for understanding the meaning of the knowledge internalization extension is related to time. Knowledge transfer is a complex and time-consuming process that requires time to obtain effective results (Szulanski et al., 2016). As seen, the process of knowledge appropriation by the receiver takes time (Ancori et al., 2000).

Therefore, in knowledge transfer short-term results are fictional. Satisfactory results appear as knowledge is assimilated, internalized by the organization (Szulanski et al., 2016). In addition, some characteristics of both the sender and receiver of knowledge may 


\section{i[CREMF}

influence both appropriation and time taken for internalization. Factors such as the sender's disseminative capacity and the receiver's absorptive capacity may affect the degree of knowledge internalization by inhibiting or fostering appropriation and reducing or increasing the time of the process.

\subsection{The Receiver's Absorptive Capacity and the Knowledge Internalization}

An organization's ability to learn new knowledge from the external environment requires sufficient technical understanding to capitalize on this knowledge. This internal capacity, also known as absorptive capacity (AC), provides the foundation on which organizations can learn from external partners (Huang et al., 2015; Jansen et al., 2005; Minbaeva et al., 2014).

For Cohen and Levinthal (1990), AC is the ability of the organization to recognize the value of external knowledge and to assimilate and apply it for business purposes. Some aspects are critical to AC, including the prior knowledge and experience accumulated by the organization that contributes to improving the ability to acquire and assimilate and the ability to reuse knowledge. Therefore, an organization that has the knowledge and prior experience similar to the intended external knowledge is more able to develop new knowledge combinations (Cohen \& Levinthal, 1990).

Subsequently, Zahra and George (2002) reconceptualized the concept of AC, which is now understood as a dynamic capability, understood as a set of routines and processes that allow the organization to acquire, assimilate, transform and exploit knowledge. In addition, the authors divided these four capacities into two dimensions: potential absorptive capacity (PACAP) and realized absorptive capacity (RACAP).

PACAP is formed by the acquisition and assimilation capacities of external knowledge. Acquisition refers to an organization's ability to identify and acquire external knowledge critical to its operations (Rakthin et al., 2016). The assimilation of new knowledge refers to the receiving firm's ability to analyze, to process, to interpret and to understand the knowledge obtained from external sources (Szulanski, 2000; Zahra \& George, 2002).

In RACAP there are the other two capabilities of organizations: the transformation and the exploitation. Transformation refers to the effort of combining the knowledge. More specifically, it is about the organizational capacity to develop and refine routines that make it easier to combine existing knowledge with newly acquired and assimilated knowledge (Patterson \& Ambrosini, 2015).

Finally, exploration refers to a firm's ability to use transferred knowledge, that is, the ability to incorporate knowledge acquired, assimilated and transformed into its operations and organizational routines for exploration and use (Patterson \& Ambrosini, 2015; Wang et al., 2017). Successful exploitation of external knowledge requires the firm not only to acquire or simulate new knowledge but to be able to apply it effectively (Huang et al., 2015).

Together, the four dimensions of absorptive capacity enable companies to exploit discoveries and knowledge (Volberda et al., 2010) and act as a capacity that affects the appropriation of transferred knowledge and the time spent in the internalization process. 


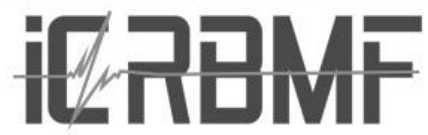

\subsection{The Sender's Disseminative Capacity and the Knowledge Internalization}

The sender's disseminative capacity (DC) is "(...) the ability and knowledge holders to transfer it efficiently, effectively and convincingly so that other individuals can understand it accurately and put their learning into practice" (Tang, Mu \& MacLachlan, 2010, p.1587). DC involves at least two main attributes: the sender's motivation to transfer knowledge (Easterby-Smith et al., 2008; Sroka et al., 2014) and the sender's ability to transfer knowledge (Mu et al., 2010; Malm, Fredriksson \& Johansen, 2016).

First, the sender must be willing to transfer knowledge and has a trusting relationship with the receiver (Cummings, 2003). The motivation to transfer knowledge is paramount to initiating the process because if the source is not comfortable sharing knowledge, it can make the relationship between the parties difficult and reduce the interest of the receiver (Sroka et al., 2014). However, well-intentioned or motivated organizations to transfer knowledge are not sufficient conditions as they may not know how to do so. This means that the ability to transfer knowledge is another critical ability of the sender's disseminative capacity and involves teaching skills ( $\mathrm{Mu}$ et al., 2010), i.e. the ability to translate and articulate knowledge so that it can be transferred clearly and convincingly, in a way that receivers can easily understand, absorb and use knowledge in their routines (Mu et al., 2010).

When the knowledge holders has a high transfer capacity (Malm et al., 2016), knowledge is more easily understood and articulated by the receiver which contributes to the internalization process. In contrast, when the source of knowledge lacking adequate capacity to transfer knowledge, the process will be marked by different interpretations of the same idea, the need for several restarts and many interruptions (Mu et al., 2010), thus, requiring a longer time for internalization. Accordingly, the source DC can affect the level of knowledge internalization and, moreover, the time is taken to internalize it (Szulanski et al., 2016).

\section{Method}

To investigate the internalization of quality practices in knowledge transfer processes in a health foundation, a qualitative, embedded and long-term cross-sectional case study was undertaken (Yin, 2017; Eisenhardt \& Graebner, 2007). The choice is based on the complexity of the knowledge transfer phenomenon, with many and intertwined variables (Eisenhardt \& Graebner, 2007). The choice of a longitudinal study lies in the fact that such studies make it possible to explore and explain the evolution and change of the phenomenon over time (Yin, 2017).

The case chosen was Ezequiel Dias Foundation - Funed, a Brazilian centenary public institution whose purpose is to research scientific and technological development, the production of medicines, and the performance of laboratory analysis.

Among the reasons for choosing the case we highlight: (i) Funed is one of the main public health, science and technology institutions in Brazil; (ii) it is one of the few public health institutions internationally recognized by several certification 
bodies, considering the rarity of quality certifications in the public sphere (Psomas Pantouvakis \& Kafetzpoulos, 2013); and (iii) Funed's relevant role in the national and public health scenario. In addition to these reasons, Funed underwent a quality certification process between 2008 and 2016, with a view to acquiring external quality certification knowledge, more specifically in the four directorates of the Foundation, namely: (i) Industrial Directorate (ID); (ii) Octávio Magalhães Institute Directorate (SD); (iii) Research and Development Directorate (R\&DD); and (iv) Planning, Management and Finance Directorate (PMD). As a result, the units of analysis are these four boards, taken as sub-cases for research on the internalization of practices. Choosing a specific case with built-in units (Yin, 2017) and of longitudinal length increases data robustness and greater validity of results (Yin, 2017).

Case research requires the use of various sources of evidence by the researcher (Yin, 2017). In-depth interviews, documents and observation were used. Table 1 specifies the main documents used in the research.

Table 1: List of documents and files used

\begin{tabular}{|l|l|}
\hline Document & \multicolumn{1}{|c|}{ Description of documents } \\
\hline Doc 1 & Ezequiel Dias Foundation - A Century of Health Promotion and Protection -2007 \\
\hline Doc 2 & Funed Quality Manual - 2016 \\
\hline Doc 3 & Funed 10 - Scenario Planning - 2006 \\
\hline Doc 4 & Funed Institutional Information - 2016 \\
\hline Doc 5 & Minutes of Quality Management System Critical Analysis - 2009 \\
\hline Doc 6 & Research and Development Board Biosafety Report - 2009 \\
\hline Doc 7 & External Diagnostic Audit Report - 2010 \\
\hline Doc 8 & Minutes of Quality Management System Critical Analysis - 2010 \\
\hline Doc 9 & Minutes of Quality Management System Critical Analysis - 2013 \\
\hline Doc 10 & Minutes of Quality Management System Critical Analysis - 2014 \\
\hline Doc 11 & Minutes of Quality Management System Critical Analysis - 2015 \\
\hline Doc 12 & Satisfaction Survey Funed Internal Audit Cycle - 2015 \\
\hline
\end{tabular}

Source: Authors

Thirteen in-depth interviews were conducted during May to September 2016. As the material underwent preliminary analysis it became apparent that the set of journals met the meaning saturation criterion (Eisenhardt \& Graebner, 2007). Thus, an interview was conducted with a representative of the consulting firm, responsible for the knowledge transfer process, in addition to interviews with employees who acted as multipliers responsible for the knowledge dissemination in Funed. At the strategic level, the directors of Funed's four directorates (R\&DD, SD, ID and PMD) were interviewed. They provided a systemic view of the transfer process and the results presented to each directorate. Finally, interviews were conducted with employees at the operational level of the Foundation who use quality practices in their daily routine. Table 2 shows the set of interviews conducted. 


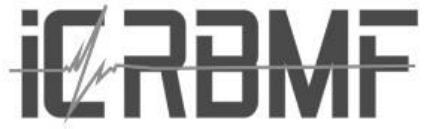

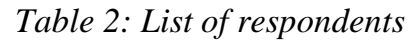

\begin{tabular}{|c|l|l|l|l|l|}
\hline Interview & \multicolumn{1}{|c|}{ Training / Position } & \multicolumn{1}{|c|}{ Acting } & Company & $\begin{array}{c}\text { Board of } \\
\text { Directors }\end{array}$ & $\begin{array}{c}\text { Time in } \\
\text { the } \\
\text { company }\end{array}$ \\
\hline E1 & Biologist / Researcher & Dissemination & Funed & R\&DD & 09 years \\
\hline E2 & Biologist / Researcher & Operational & Funed & R\&DD & 09 years \\
\hline E3 & Biologist / Director & Strategic & Funed & R\&DD & 30 years \\
\hline E4 & $\begin{array}{l}\text { Pharmacist / } \\
\text { Quality Analyst }\end{array}$ & Dissemination & Funed & ID & 11 years \\
\hline E5 & Production Technician & Operational & Funed & ID & 09 years \\
\hline E6 & Pharmacist / Director & Strategic & Funed & ID & 09 years \\
\hline E7 & $\begin{array}{l}\text { Biologist / } \\
\text { Quality Analyst }\end{array}$ & Dissemination & Funed & SD & 09 years \\
\hline E8 & $\begin{array}{l}\text { Biologist / } \\
\text { Laboratory Analyst }\end{array}$ & Operational & Funed & SD & 15 years \\
\hline E9 & Biologist / Director & Strategic & Funed & SD & 29 years \\
\hline E10 & $\begin{array}{l}\text { Administrator / } \\
\text { Quality Analyst }\end{array}$ & Dissemination & Funed & PMD & 08 years \\
\hline E11 & Maintenance Technician & Operational & Funed & PMD & 06 years \\
\hline E12 & Administrator / Director & Strategic & Funed & PMD & 09 years \\
\hline E13 & Consultant & Dissemination & Consulting & ------- & ------ \\
\hline Sourc: A & & & & & \\
\hline
\end{tabular}

Source: Authors

After data collection, data analysis was performed based on the content analysis technique (Bardin, 2009). At first, all documents and files were sorted and selected according to their relevance to the elucidation of the phenomenon. These were then joined by the full transcribed interviews and the field observations. In total terms, the search corpus contained about 200 pages. Three analytical categories and subcategories derived from literature were established for data analysis, namely: (i) Knowledge internalization by the receiver (appropriation of knowledge and time taken for internalization); (ii) Disseminative capacity of the sender; and (iii) absorptive capacity of the receiver. In addition to content analysis, NVivo software was used to highlight some relationships between the constructs. After categorizing the contents in the categories and subcategories, the data were analyzed and interpreted.

\section{RESULTS}

\subsection{Context of the implementation of the Quality Management System at Funed}

The Ezequiel Dias Foundation is a centenary public health institution in the state of Minas Gerais, Brazil, composed of four directorates: Industrial Directorate, Octávio Magalhães Institute Directorate, Research and Development Directorate and Planning, Management and Finance Directorate. The purpose of Industrial Directorate (ID) is to develop and produce medicines, serums and vaccines to the Brazilian's public care system. Octávio Magalhães Institute Directorate performs laboratory analysis on Sanitary, Epidemiological and Environmental Surveillance, so this directorate is identified in this paper 
as Surveillance Directorate (SD). The purpose of Research and Development Directorate (R\&DD) is to develop scientific and technological research in the field of public health. The purpose of the Planning, Management and Finance Directorate (PMD) is to carry out activities related to people management, logistics, financial and supply management.

The process of implementing the Quality Management System in Funed's four directorates began in 2008 under the guidance of an external consultant focused on the dissemination of quality practices and the implementation of ISO 9001.

In the Research and Development Directorate (R\&DD), the implementation of quality management practices required more and more intense work compared to other directorates. This may be partly explained by a distinctive feature on this directorate: the employees had no prior knowledge or experience related to quality practices. Of the characteristics of R\&DD stands a very strong resistance in the period of quality practices implementation, which made the process difficult. "Most researchers did not want to participate in the process and did not facilitate deployment. [There was] a lot of resistance, a lot of resistance, everybody (...)" (E 3). Another complete report saying that "(...) the researchers did not want to [apply the quality practices] (...) they thought it would make the research process difficult because the researchers were not used to follow routine procedures" (E 2).

Similarly, the Planning, Management and Finance Directorate (PMD), although an administrative directorate, presented a very similar context to R\&DD at the time of implementation. PMD also had no prior experience or knowledge of quality practices. Both characteristics result in similar consequences to R\&DD: first, the work of implementing quality practices started from scratch and, thus, requiring the multipliers and internal consultants to perform more frequently. Finally, during the implementation process, there is a clear resistance to quality practices. "In the beginning, the benefits were not immediately seen. The attitude was: it has to be done, so let's do it. The results come with the maturation of the system. So, in the early years, people still couldn't see how much it would benefit Funed" (E 13).

In both directorates, their similarities eventually hampered the implementation of quality practices, which required greater training intensity, frequent meetings, greater dissemination of multipliers and external consultants, and more time for the vision of R\&DD and PMD change concerning quality tools.

The Industrial Directorate (ID) had already tried some quality practices applied to its processes, although they were not widespread in all areas. ID's experience and some previous knowledge of quality practices have minimized possible resistance to the implementation of new quality practices based on ISO 9001. But a distinctive feature of ID has an impact on the attribution of value to quality standards: the drug production activity is one that follows clear and previously established standard procedures. This means that the process of implementing the quality practices established by ISO 9001 was not a strange one and did not greatly impact the routine of the directorate. "(...) we were already heavily charged by other standards. ( ...) [the previous experience] only helped, because we already adopted quality practices, it was not new anymore, so it was not difficult to implement" (E 5).

Finally, in the Octávio Magalhães Institute Directorate named in this paper as Surveillance Directorate (SD), there was previous experience and knowledge of quality practices, as was also observed in ID. SD is responsible for the highly complex laboratory diagnosis of dozens of diseases/illnesses that affect the population, and the directorate was 
already used to have their processes periodically audited by external organisms. "As in ID, the application of quality practices already existed in SD since 2003, I guess (...). The culture of quality was already well established. Employees were already aware, not necessarily in [ISO] 9001 but of other standards" (E 7).

In the four units analyzed, it was observed that the directorates were similar to the pairs, that is, the characteristics of R\&DD and PMD are similar and the results of the implementation of the practices make it a standard. The same is true of the two other boards, ID and SD, only with opposite characteristics and results. Table 3 summarizes the characteristics of Funed's quality certification process.

Table 3: The process of implementing quality practices at Funed

\begin{tabular}{|c|c|c|c|c|}
\hline Features & R\&DD & PMD & ID & SD \\
\hline $\begin{array}{c}\text { Prior knowledge of } \\
\text { practice }\end{array}$ & $\begin{array}{c}\text { Lack of } \\
\text { experience }\end{array}$ & $\begin{array}{c}\text { Lack of } \\
\text { experience }\end{array}$ & $\begin{array}{c}\text { Previous } \\
\text { experience }\end{array}$ & $\begin{array}{c}\text { Previous } \\
\text { experience }\end{array}$ \\
\hline Activity Type & Not routine & Routine & Routine & Routine \\
\hline External regulation & Low regulation & Low regulation & High regulation & High regulation \\
\hline $\begin{array}{c}\text { Implantation } \\
\text { reactions }\end{array}$ & $\begin{array}{c}\text { High initial } \\
\text { resistance }\end{array}$ & $\begin{array}{c}\text { High initial } \\
\text { resistance }\end{array}$ & $\begin{array}{c}\text { Low initial } \\
\text { resistance }\end{array}$ & $\begin{array}{c}\text { Low initial } \\
\text { resistance }\end{array}$ \\
\hline
\end{tabular}

Source: Authors

\subsection{Evolution in the adoption of quality practices in post-certification Funed}

The quality management system on post-certification Funed directorates does not bear much resemblance to what was reported during the implementation period. Funed was certified in ISO 9001 at the end of 2010, almost two years after the beginning of the implementation of quality practices in the Foundation. External audit cycles are annual, meaning that all four directorates are periodically audited to verify that the requirements set by the standard continue to be maintained in the organization's routine.

However, in 2009, at the time of the first cycle of internal audits at Funed, the average number of non-conformities evidenced was 10 (ten) appointments per directorate. Data from the internal audit conducted in 2015 show that this average has been reduced by some boards by more than 50\% (Minutes of Quality Management System Critical Analysis; 2015).

Both ID and SD were the directorates that presented the largest decrease in the average of non-conformities evidenced in the internal audits are therefore more efficient than R\&DD and PMD. The average non-conformities of ID and SD also declined more significantly over time, while R\&DD and PMD maintained a high average over a longer period.

Currently, several frames of resistance and difficulties reported during the implementation period are no longer characterized as the reality of the Foundation. For example, in R\&DD the researchers who at the beginning of the process did not want the implementation of quality practices in the laboratory activities have changed this view today. "The resistance has been decreasing as time went by. At first, there was a lot of resistance, but nowadays we see that it works. People today understand better, and younger employees have no resistance at all. They know the certification was beneficial, they saw the advances within of laboratories, saw the advances in the managerial part (...)" highlights the interviewee 1 . 
Similarly, PMD is undergoing profound changes from the beginning of quality practices certification process, mainly concerning to the resistance and the value attributed to these practices. "PMD results today are much better, not only the results but the quality of the results obtained are better as well" (E 12). "The time of certification contributed, we [PMD employees] were internalizing some practices over time. The more time goes by the deeper we use the tools and better is our perception of quality" (E 10).

In ID, the application of quality practices is already visible in the results. "(...) had lots of positives things. At the beginning [in 2008], for example, sometimes the person did not have control of her records, today she worries" (E 6). Another report complements saying "these [quality] practices do add a lot of value" (E 4). Also, some resistance observed at the beginning of the process is no longer presented. "I think today's employees accept more, I do not see resistance (...) they recognize that [quality] practices are valid, that they add value" (E 4).

Finally, SD has a similar picture to ID after the certification process, a low resistance and a value view attributed to quality practices. The SD employees realize the importance of quality practices in their processes and the value they add to their results. "The importance of quality practices application is visible; we were elevated to a successful status in Brazil" (E 9).

Table 4: Adoption of post-certification practices

\begin{tabular}{|c|c|c|c|c|}
\hline $\begin{array}{c}\text { Features and } \\
\text { Results } \\
\end{array}$ & R\&DD & PMD & ID & SD \\
\hline \multirow{2}{*}{$\begin{array}{l}\text { Reactions to the } \\
\text { use of practices }\end{array}$} & $\begin{array}{l}\text { High initial } \\
\text { resistance }\end{array}$ & $\begin{array}{l}\text { High initial } \\
\text { resistance }\end{array}$ & $\begin{array}{l}\text { Low initial } \\
\text { resistance }\end{array}$ & $\begin{array}{l}\text { Low initial } \\
\text { resistance }\end{array}$ \\
\hline & $\begin{array}{l}\text { Low current } \\
\text { resistance }\end{array}$ & $\begin{array}{c}\text { Low current } \\
\text { resistance }\end{array}$ & $\begin{array}{l}\text { Low current } \\
\text { resistance }\end{array}$ & $\begin{array}{c}\text { Low current } \\
\text { resistance }\end{array}$ \\
\hline \multirow{2}{*}{$\begin{array}{c}\text { Value view of } \\
\text { quality practices }\end{array}$} & $\begin{array}{c}\text { Low initial value } \\
\text { view }\end{array}$ & $\begin{array}{c}\text { Low initial value } \\
\text { view }\end{array}$ & $\begin{array}{l}\text { High initial value } \\
\text { view }\end{array}$ & $\begin{array}{l}\text { High initial value } \\
\text { view }\end{array}$ \\
\hline & $\begin{array}{l}\text { High current value } \\
\text { view }\end{array}$ & $\begin{array}{l}\text { High current value } \\
\text { view }\end{array}$ & $\begin{array}{l}\text { High current value } \\
\text { view }\end{array}$ & $\begin{array}{c}\text { High current value } \\
\text { view }\end{array}$ \\
\hline
\end{tabular}

Source: Authors

\subsection{Discussion}

\subsubsection{The role of absorptive capacity in the internalization of quality practices}

The analysis of the sub-cases suggests that R\&DD and PMD employees had no previous knowledge and no previous experience with the application of quality practices, led them to ignore the benefits of applying the new practices which may have contributed to a lower capacity in acquiring, assimilating, transforming and applying new knowledge (Kocoglu et al., 2015). Therefore, as the benefits of applying the new practices were not known in these directorates, a longer internalization time was necessary. The value recognition of quality practices in R\&DD and PMD only happened with the new knowledge practical application in the routine and then, the first positive outcomes started to show up (Szulanski, 2000) as pointed out in the reports.

On the other hand, the analysis of the data shows that, in ID and SD, the implementation scenario of the quality practices was quite different, since these directorates already had 


\section{i[CREMF}

previous knowledge and previous experience with the application of similar quality practices, pre-existing knowledge stock in these recipient units (Huang et al., 2015). Thus, resistance to implantation was felt in a milder way which may have contributed positively to the application of practices from the beginning.

Thereby, the matrix coding feature in the NVivo software allowed the visualization of significant results (Graph 1), matrix coding two variables of the theoretical research model absorptive capacity (AC) and knowledge appropriation.

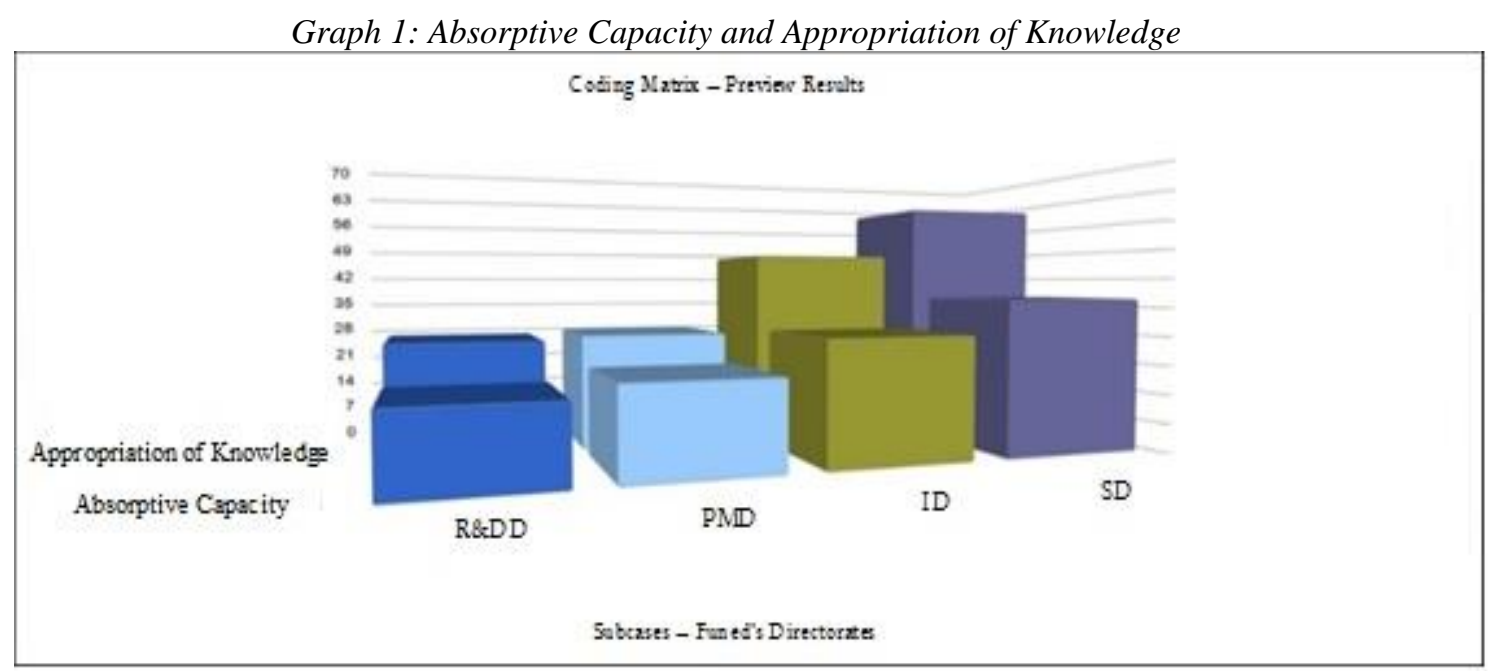

Source: Elaborated by the authors using NVivo software.

Cross-tabulation allows us to observe a different level for the directorates, in which R\&DD and PMD have similar characteristics concerning knowledge appropriation and AC, while ID and SD approach each other. Through the coding matrix in Graph 1, it is observed that the directorates that have a higher level of AC - ID and SD - also have the highest level of knowledge appropriation. On the other hand, the opposite situation is confirmed. Boards that have a lower AC - R\&DD and PMD - also have a lower level of ownership. The relationship is not proportional but suggests an influence of $\mathrm{AC}$ in the appropriation of knowledge.

Taking all this result together including the analysis of interviews, analyzed documents and field notes, it can be deduced that a greater AC found in ID and SD positively contributed to greater knowledge appropriation in these directorates. Based on these results we formulate the first proposition as a result of the research:

P1a: The receiver's absorptive capacity is positively associated with greater appropriation of knowledge.

Moreover, if we analyze the Funed case, the directorates practically tripled the records of preventive actions over the years (2010 to 2015), showing a progressive increase in the application of this practice. These data demonstrate that not only the quality practices were routinely introduced, but also their application increased significantly over the years. Therefore, it is possible to verify that Funed is acting more proactively, that is, taking measures before non-compliance occurs. In this sense, the literature highlights that positive 


\section{i[CREMF}

results take time to notice (Szulanski, 2000) and positive perceptions about the value of practice over time, reflect its internalization and facilitate its persistence and stability over time (Kostova \& Roth, 2002).

This positive result in the appropriation of quality practices over time is perceived in the four directorates. The number of non-conformities evidenced over the years $(2009-2015)$ showed a significant decrease in all boards without exception.

However, ID and SD presented a lower average of non-conformities compared to R\&DD and PMD. The average non-conformities of ID and SD declined more significantly over time, while R\&DD and PMD maintained a high average over a longer period. In this sense, the data shows that R\&DD and PMD required more time to have an average of non-conformities similar to ID and SD.

Thus, the directorates that showed greater AC (ID and SD) possessed a higher level of previous knowledge (Huang et al., 2015) and needed less time to internalize it (Szulanski et al., 2016). The stock of knowledge and previous experience of these boards allowed a more efficient use of the transferred knowledge (Cohen \& Levinthal, 1990). Based on the evidence we formulate the second proposition:

P1b: The receiver's absorptive capacity is inversely related to the time taken for knowledge internalization.

Thus, it should be noted that a larger absorptive capacity contributes to greater knowledge appropriation and reduction of the internalization time by the receiver. Thus, together with the sender disseminative capacity, absorptive capacity is relevant for the internalization of knowledge from knowledge transfer process.

\subsubsection{The role of disseminative capacity in the internalization of quality practices}

Two attributes are considered essential to disseminative capacity (DC): the ability to transfer the new knowledge and the motivation of the company to do so. About source's motivation (consulting and internal multipliers) to share and pass on the knowledge, there was no fear at all in relation to possible spillovers or improper use of knowledge (opportunistic behavior) (Easterby-Smith et al., 2008; Malm et al., 2016).

However, a well-intentioned organization to transfer knowledge is not a sufficient condition, as knowledge may not be able to do so, and this seems to be a determining feature in the knowledge internalization process. The narrative of the R\&DD and PMD sub-cases suggests that the transfer of knowledge during the implementation of the practices went through several difficulties, such as the lack of previous knowledge and experience of employees and multipliers, and the consultants' difficulties in finding suitable examples to the reality of R\&D activity. In other words, the sender's low ability to transfer the quality practices has made the dissemination process longer and harder, compromising negatively the appropriation of knowledge by employees and contributing to a more elastic time in the internalization of practices transferred in these directorates.

The sender's low ability to transfer knowledge (external consultants and internal multipliers) seems to explain the low value attributed to the practice by the employees, because without the ability to teach or communicate effectively, the process can generate 


\section{i[CREMF}

different interpretations of the practice, reworking and interruptions (Mu et al., 2010) thus, demanding a longer time for internalization.

In the other two directorates, ID and SD, it is clear that the employees and multipliers previous knowledge and experience with quality practices are critical to the successful implementation. The analysis of the data indicates that the employees of these directorates attributed value to the practice due to positive results from the application of similar practices in their routine (Kostova \& Roth, 2002), contributing to making internalization faster and more successful. Therefore, in ID and SD the greater disseminative capacity allowed the appropriation of knowledge in a shorter time compared to the previous two directorates.

Extending and corroborating the previous analyzes, using NVivo matrix coding, as shown in Graph 2, the cross-tabulation between the DC constructs and knowledge appropriation allows us to observe that in the R\&DD and PMD sub-cases the role of disseminative capacity was similar and lower than in the ID and SD subcases, as well as the level of knowledge appropriation in these pairs of units. The analysis of Graph 2 is not proportional but suggests that the disseminative capacity is related to Funed's appropriation of knowledge.

Graph 2: Disseminative Capacity and Appropriation of Knowledge

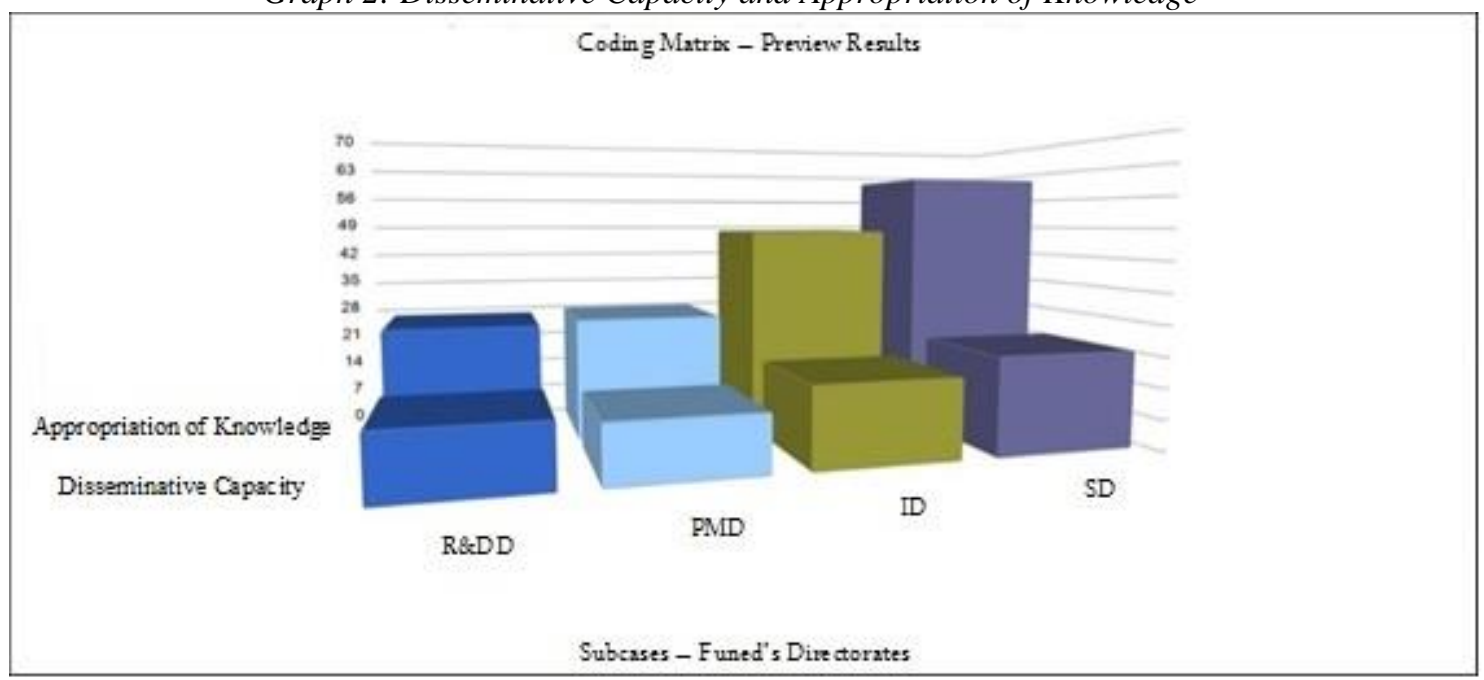

Source: Elaborated by the authors using NVivo software.

Thus, in the case of Funed from the data set can be established that the sub-cases (directorates) who had a higher level of ownership of knowledge are those who had access to a larger sender's DC, especially the ability to transfer knowledge. Based on this evidence, we suggest here the third proposition as a result of the research:

P2a: Sender's disseminative capacity is positively associated with greater appropriation of knowledge by the receiver.

Another important data presented in the description of the cases, Graph 2, allows us to observe the average of non-conformities evidenced in the internal audits over the years. The graph shows that ID and SD had a lower average of nonconformities in the first years of 


\section{i[L羽MF}

internal audits, whereas, on the other hand, R\&DD and PMD had a higher average. Moreover, Graph 2 indicates that in the first years of the audit, considering from 2009 to 2012, the average nonconformities remained high in R\&DD and PMD while ID and SD had a much lower average. Thus, the analysis of Graph 2 allows us to state that R\&DD and PMD took longer to internalize the practices compared to ID and SD.

Also according to the collected data, the ability to transfer from the source contributed positively to the acceleration of the internalization process, especially in ID and SD, since the internal multipliers already had previous knowledge and previous experience with the application of quality practices. Multipliers in turn, trained by external consultants, used their knowledge about the specifics of the directorates and the routine of the areas to translate, adapt in an understandable way and disseminate knowledge (Mu et al., 2010). This way, the employees of ID and SD could understand, absorb and apply the practices faster than the employees of R\&DD and PMD.

In this context, it is possible to observe in the ID and PMD sub-cases, based on the data analysis, that the sources of knowledge investigated - the external consultancy and the internal multipliers - present a larger DC of quality practices, accelerating the process of internalization in these directorates. Thus, the greater disseminative capacity of the source contributes not only to a greater appropriation of knowledge but also to a reduction of the internalization time. Considering the presented evidence, we formulate here a fourth proposition:

P2b: Sender's disseminative capacity is inversely associated with the receiver's time to knowledge internalization.

\section{Conclusion}

Given the objective of evaluating the role of the absorptive capacity (AC) of the receiver and the disseminative capacity (DC) of the sender in the internalization of quality practices (appropriation and time spent) the findings suggest that directorates that had a higher level of AC (ID and SD) had a higher level of practices ownership. The ID and SD sub-cases suggest that previous knowledge and previous experience with quality practices have enabled employees to see value in new knowledge which contributed to reducing initial resistance, facilitating the internalization process in these directorates and allowing a short internalization process time. The opposite was perceived in the R\&DD and PMD units. The evidence found allowed us to conclude that a larger $\mathrm{AC}$ of the receiver contributed to a greater appropriation of knowledge and reduced the time taken for internalization, allowing the formulation of two other research propositions (P1 and P1a).

The findings also suggest that the directorates whose internal multipliers showed a higher DC (ID and SD) were able to provoke greater enthusiasm for internalization and to lead the transfer process more effectively. Thus, the larger DC resulted in the internalization of knowledge by the receiver in less time and with a higher level of ownership in these boards. The conclusion is that a larger source DC contributes to a greater appropriation of knowledge by the receiver and a reduction in the internalization time, allowing the formulation of the first two propositions as research results (P2 and $\mathrm{P} 2 \mathrm{a})$. 


\section{itRenEF}

The main contribution of this study was to provide a deeper understanding of the internalization of knowledge as a multidimensional variable, taking into account the dimensions of knowledge appropriation and internalization time. In addition, we formulate a theoretical framework that can be tested empirically in other studies. From an empirical perspective, understanding the role of sender's DC and receiver's AC can help organizations achieve more agile and lasting results from the knowledge transfer process by basing their external knowledge acquisition processes on the consideration not only that internalization matter but also that internalization depends on the capacity of its employees and the capacity of the external source of knowledge.

One of the limitations of this research is the use of a single case study with the investigation of embedded cases (Yin, 2017), limiting the generalization of the results found. Also as a limiter, the studied context (quality practices) is added. It would be interesting for future research to study the knowledge internalization process using multiple cases, allowing pointing out differences between organizations. Another recommendation is a more extensive study that provides the basis for testing the propositions formulated here.

\section{Acknowledgement}

We appreciate the support of Fundação Ezequiel Dias (FUNED) and the financial support of Fundação de Amparo á Pesquisa do Estado de Minas Gerais (FAPEMIG) and Coordination for the Improvement of Higher Education Personnel (CAPES) for this research.

\section{References}

Ancori, B., Bureth, A., \& Cohendet, P. (2000). The economics of knowledge: the debate about codification and tacit knowledge. Industrial and Corporate Change, 9(2), 255287.

Argote, L., \& Fahrenkopf, E. (2016). Knowledge transfer in organizations: The roles of members, tasks, tools, and networks. Organizational Behavior and Human Decision Processes, 136, 146-159.

Bardin, L. (2009). Analysis and content (Updated revised edition). Lisbon: Editions, v. 70

Cohen, W. M., \& Levinthal, D. A. (1990). Absorptive Capacity: A New Perspective on Learning and Innovation. Strategic Learning in a Knowledge Economy, 128-152.

Cummings, J. (2003). Knowledge sharing: a review of the literature. In Enhancing development effectiveness through excellence and independence in evaluation.

Cummings, J. L., \& Teng, B. S. (2003). Transferring R \& D knowledge: The key factors affecting knowledge transfer success. Journal of Engineering and Technology Management - JET-M, 20(1-2 SPEC.), 39-68.

Easterby-Smith, M., Lyles, M. A., \& Tsang, E. W. K. (2008). Inter-organizational knowledge transfer: Current themes and future prospects. Journal of Management Studies, 45(4), 677-690.

Eisenhardt, K. M., \& Graebner, M. E. (2007). Theory building from cases: Opportunities and challenges. Academy of Management Journal, 50(1), 25-32.

Huang, K. F., Lin, K. H., Wu, L. Y., \& Yu, P. H. (2015). Absorptive capacity and 


\section{i[CR日F}

autonomous R\&D climate roles in firm innovation. Journal of Business Research, 68(1), 87-94.

Jansen, J. J. P., Van Den Bosch, F. A. J., \& Volberda, H. W. (2005). Managing potential and realized absorptive capacity: How do organizational antecedents matter? Academy of Management Journal, 48(6), 999-1015.

Kocoglu, I., Akgün, A. E., \& Keskin, H. (2015). The Differential Relationship between Absorptive Capacity and Product Innovativeness: A Theoretically Derived Framework. International Business Research, 8(7), 108-120.

Kostova, T., \& Roth, K. (2002). Adoption of an organizational practice by subsidiaries of multinational corporations: Institutional and relational effects. Academy of Management Journal, 45(1), 215-233.

Malm, A. M., Fredriksson, A., \& Johansen, K. (2016). Bridging capability gaps in technology transfers within related offsets. Journal of Manufacturing Technology Management, 27(5), 640-661.

Minbaeva, D., Pedersen, T., Björkman, I., Fey, C. F., \& Park, H. J. (2014). MNC knowledge transfer, subsidiary absorptive capacity and HRM. Journal of International Business Studies, 45(1), 38-51.

Mu, J., Tang, F., \& MacLachlan, D. L. (2010). Absorptive and disseminative capacity: Knowledge transfer in intra-organization networks. Expert Systems with Applications, 37(1), 31-38.

Patterson, W., \& Ambrosini, V. (2015). Configuring absorptive capacity as a key process for research intensive firms. Technovation, 36, 77-89.

Psomas, E. L., Pantouvakis, A., \& Kafetzopoulos, D. P. (2013). The impact of ISO 9001 effectiveness on the performance of service companies. Managing Service Quality, 23(2), 149-164.

Rakthin, S., Calantone, R. J., \& Wang, J. F. (2016). Managing market intelligence: The comparative role of absorptive capacity and market orientation. Journal of Business Research, 69(12), 5569-5577.

Sroka, W., Cygler, J., \& Gajdzik, B. (2014). The Transfer of Knowledge in IntraOrganizational Networks: A Case Study Analysis. Organizacija, 47(1), 24-34.

Szulanski, G. (2000). The Process of Knowledge Transfer: A Diachronic Analysis of Stickiness. Organizational Behavior and Human Decision Processes, 82(1), 9-27.

Szulanski, G., Ringov, D., \& Jensen, R. J. (2016). Overcoming stickiness: How the timing of knowledge transfer methods affects transfer difficulty. Organization Science, 27(2), 304-322.

Tang, F., Mu, J., \& MacLachlan, D. L. (2010). Disseminative capacity, organizational structure and knowledge transfer. Expert Systems with Applications, 37(2), 1586-1593.

Tsai, M. Ten, \& Lee, K. W. (2006). A study of knowledge internalization: From the perspective of learning cycle theory. Journal of Knowledge Management, 10(3), 57-71.

Volberda, H. W., Foss, N. J., \& Lyles, M. A. (2010). Absorbing the concept of absorptive capacity: How to realize its potential in the organization field. Organization Science, 21(4), 931-951.

Wang, Y., Guo, B., \& Yin, Y. (2017). Open innovation search in manufacturing firms: the role of organizational slack and absorptive capacity. Journal of Knowledge Management, 21(3), 656-674. 
Wipawayangkool, K., \& Teng, J. T. C. (2016). Elements of Innovation Cultures. Knowledge and Process Management, 14(3), 190-202. https://doi.org/10.1002/kpm

Yin, RK (2017). Case study research and applications: Design and methods. Sage publications.

Zahra, S. A., \& George, G. (2002). Absorpitive Capacity: A Review, Reconceptualization and Extension. Academy of Management Review, 27(2), 185-203. 